\title{
Process evaluation of a randomised controlled trial of a diabetes prevention intervention in Dutch primary health care: the SLIMMER study
}

\author{
Ellen Jl van Dongen ${ }^{1}{ }^{*}$, Geerke Duijzer ${ }^{1}$, Sophia C Jansen ${ }^{2}$, Josien ter Beek ${ }^{2}$, \\ Johanna M Huijg ${ }^{3}$, Joanne N Leerlooijer ${ }^{1}$, Gerrit J Hiddink ${ }^{4}$, Edith JM Feskens ${ }^{1}$ \\ and Annemien Haveman-Nies ${ }^{1,2}$ \\ 'Wageningen University, Division of Human Nutrition and Academic Collaborative Centre AGORA, PO Box 8129 , \\ 6700 EV Wageningen, The Netherlands: ${ }^{2}$ GGD Noord- en Oost-Gelderland (Community Health Service), \\ Warnsveld, The Netherlands: ${ }^{3}$ Leyden Academy on Vitality and Ageing, Leiden, The Netherlands: ${ }^{4}$ Wageningen \\ University, Strategic Communication, Sub-department Communication, Philosophy and Technology: Centre for \\ Integrative Development, Social Sciences, Wageningen, The Netherlands
}

Submitted 24 December 2015: Final revision received 23 March 2016: Accepted 27 April 2016: First published online 3 June 2016

\begin{abstract}
Objective: To investigate (i) how the SLIMMER intervention was delivered and received in Dutch primary health care and (ii) how this could explain intervention effectiveness.

Design: A randomised controlled trial was conducted and subjects were randomly allocated to the intervention (10-month combined dietary and physical activity intervention) or the control group. A process evaluation including quantitative and qualitative methods was conducted. Data on process indicators (recruitment, reach, dose received, acceptability, implementation integrity and applicability) were collected via semi-structured interviews with health-care professionals ( $n$ 45) and intervention participant questionnaires ( $n$ 155).

Setting: SLIMMER was implemented in Dutch primary health care in twenty-five general practices, eleven dietitians, nine physiotherapist practices and fifteen sports clubs.

Subjects: Subjects at increased risk of developing type 2 diabetes were included. Results: It was possible to recruit the intended high-risk population (response rate $54 \%$ ) and the SLIMMER intervention was very well received by both participants and health-care professionals (mean acceptability rating of 82 and 80, respectively). The intervention programme was to a large extent implemented as planned and was applicable in Dutch primary health care. Higher dose received and participant acceptability were related to improved health outcomes and dietary behaviour, but not to physical activity behaviour.

Conclusions: The present study showed that it is feasible to implement a diabetes prevention intervention in Dutch primary health care. Higher dose received and participant acceptability were associated with improved health outcomes and dietary behaviour. Using an extensive process evaluation plan to gain insight into how an intervention is delivered and received is a valuable way of identifying intervention components that contribute to implementation integrity and effective prevention of type 2 diabetes in primary health care.
\end{abstract}

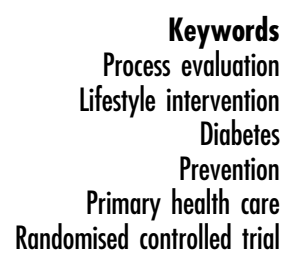

Keywords

Process evaluation Diabetes

Prevention

(a)
Over the last two decades, many large-scale randomised controlled trials have shown that type 2 diabetes can be delayed or prevented by lifestyle intervention in individuals at high risk of this disease ${ }^{(1-8)}$. Many of these interventions have been implemented in real-world settings and have shown significant reductions in weight but inconclusive results for metabolic indicators of diabetes risk $^{(9-12)}$.
However, implementation of interventions in the real world is often complex, as they are not delivered in controlled environments and thus are influenced by a multitude of factors (e.g. limited resources and finance). Therefore, a comprehensive evaluation approach is required to identify the combination of most effective intervention components for preventing type 2 diabetes $^{(9,10,13,14)}$. The scope of the 
evaluation approach needs to be broadened from only assessing effectiveness to also getting insight into the delivery of an intervention; that is, elucidating the aspects that explain what works, how and why ${ }^{(15,16)}$. A process evaluation, therefore, can enhance confidence in conclusions about intervention effectiveness ${ }^{(17)}$.

Several reviews have identified intervention components associated with increased intervention effectiveness. A review by Greaves et $a l .{ }^{(18)}$ showed that greater intervention effectiveness in dietary and physical activity (PA) interventions to prevent type 2 diabetes was associated with targeting both diet and PA, mobilising social support, using behaviour change techniques (e.g. self-monitoring, goal setting, relapse prevention and individual tailoring) and having a clear plan to support maintenance of behaviour change. Also, providing higher-intensity interventions was associated with greater intervention effectiveness ${ }^{(18,19)}$. There were no clear associations between intervention effectiveness and setting, delivery mode (e.g. group-based, individual or mixed), delivery provider or study population $^{(18,19)}$. Another systematic review on interventions to increase PA in adults aged 55-70 years found no relationship between intervention effectiveness and delivery mode or intervention intensity. However, it was concluded that tailoring the intervention to participants may be important ${ }^{(20)}$. Furthermore, a meta-regression on weight management programmes showed that greater weight loss was associated with counting calories (self-monitoring), providing at least some contact with a dietitian and facilitating social comparisons ${ }^{(21)}$.

In the Netherlands, the original Study on Lifestyle intervention and Impaired glucose tolerance Maastricht $(\mathrm{SLIM})^{(4)}$ was translated into the SLIMMER diabetes prevention intervention (SLIM iMplementation Experience Region Noord- en Oost-Gelderland) for Dutch primary health care $^{(22)}$, pilot-tested ${ }^{(23)}$, implemented on a large scale and tested in a randomised controlled trial. This intervention proved to be effective: improvements in fasting insulin, weight reduction, dietary intake and PA were found at the end of the intervention (12 months) and these were maintained at 18 months ${ }^{(24)}$. The aim of the present paper is twofold: to investigate (i) how the SLIMMER intervention was delivered and received in Dutch primary health care and (ii) how this could explain intervention effectiveness. This was done by conducting a process evaluation including several process measures (recruitment, reach, dose received, acceptability, implementation integrity and applicability).

\section{Methods}

\section{Study design and setting}

The SLIMMER study was a randomised controlled intervention study, carried out in Apeldoorn and Doetinchem, two middle-sized cities located in the eastern part of the
Netherlands. The total duration of the study was 1.5 years with an intervention period of 10 months and measurements at baseline (T0), at the end of the intervention (12 months, T1) and six months after the end of the intervention (18 months, T2). Recruitment took place between October 2011 and September 2012 in three consecutive groups for logistical reasons. The last measurements were performed in March 2014. The intervention was implemented in Dutch primary health care, involving general practitioners, practice nurses, dietitians, physiotherapists and local sports clubs. Subjects were randomised to either the SLIMMER intervention or the control group. Subjects in the control group received usual health care as provided by general practitioners and practice nurses (this ranged from no consultations to one to four consultations per year) and written information on a healthy lifestyle. The study design and lifestyle intervention programme have been reported in detail elsewhere ${ }^{(25)}$. The study protocol was approved by the Wageningen University Medical Ethics Committee and all subjects gave their written informed consent before the start of the study. The SLIMMER study is registered with ClinicalTrials.gov (identifier NCT02094911).

\section{Study population}

Study subjects were recruited by general practitioners and practice nurses from their patient registration database, using either a laboratory glucose test or the Dutch Diabetes Risk Test $^{(26)}$. The inclusion criteria were: (i) aged between 40 and 70 years at screening; (ii) impaired fasting glucose $(6 \cdot 1-6.9 \mathrm{mmol} / \mathrm{l})^{(27)}$ or an elevated/high risk of type 2 diabetes (a Diabetes Risk Test score of $\geq 7$ points) ${ }^{(26)}$; (iii) willing and able to participate in the study for at least 1.5 years; and (iv) able to speak and understand the Dutch language. Exclusion criteria were, among others, known diabetes and any severe cardiovascular or psychiatric disease. Criteria were checked using electronic medical records. General practitioners invited eligible patients to participate in the SLIMMER study and a short non-response survey was conducted if patients were not willing to participate.

\section{Lifestyle intervention programme}

The SLIMMER intervention resembled the original SLIM intervention $^{(4)}$ and consisted of a 10-month combined dietary and PA lifestyle intervention, including case management and a maintenance programme. The SLIMMER intervention was suitable for application in practice, as it was not very different from the regular functioning and professional performance of Dutch general practitioners, practice nurses, dietitians and physiotherapists ${ }^{(23)}$. Minimal training and a detailed implementation manual were provided during a two-hour SLIMMER kick-off training session for health-care professionals (HCP) involved in implementation of the intervention. This training was attended by $68 \%$ of general practices, $82 \%$ of 
dietitians and all physiotherapy practices. HCP who did not attend the training session were visited individually. HCP indicated that they felt well informed and prepared to implement the intervention after this training session. The standardised SLIMMER intervention was tailored to participants' individual needs. Details of the SLIMMER lifestyle intervention programme are given in Table 1 and described below.

\section{Dietary intervention}

The dietary intervention consisted of individually tailored dietary advice given in five to eight individual consultations and one group session. The aim was to adopt, step by step, a sustainable healthy dietary pattern according to the Dutch dietary guidelines ${ }^{(28)}$. Furthermore, it was aimed to reduce body weight by $5-10 \%$. Dietary advice was given by a primary health-care dietitian, trained in motivational interviewing and using positive feedback. Goals for behaviour change were set with participants at each consultation, evaluated in the next one, and adjusted if necessary.

\section{Physical activity intervention}

The PA intervention consisted of a combined aerobic and resistance exercise programme, supervised by a physiotherapist. The aim was to obtain and maintain an active lifestyle; that is, moderate-intensity PA for at least $30 \mathrm{~min} / \mathrm{d}$ at least five days per week. PA recommendations were based on Dutch guidelines for PA in type 2 diabetes patients ${ }^{(29)}$. Participants had free access to group-based training sessions and were encouraged to participate for at least one hour per week (maximum of two hours per week; a total of forty to eighty lessons). In addition, physiotherapists gave individually tailored advice on how to increase PA during leisure time and goals were set.

\section{Case management}

Practice nurses were appointed as case managers of the intervention programme to enhance participant compliance and the feasibility of implementation. They referred participants to the dietitian and the physiotherapist at the start of the programme. Furthermore, they contacted dietitians, physiotherapists and intervention participants twice during the programme to facilitate contact among HCP, detect and solve problems, and motivate and encourage participants.

\section{Maintenance programme}

A maintenance programme was added to the combined lifestyle intervention to guide participants in the process of maintaining lifestyle behaviour change in an independent and sustainable manner ${ }^{(30)}$. This maintenance programme was implemented during the last two months of the intervention period and consisted of: (i) intermediate evaluations by dietitians and physiotherapists to provide feedback and stimulate self-management; (ii) sports clinics at local sports clubs to introduce participants to several sports activities (the number of sports clinics ranged between two to seven per participant); (iii) final interviews with dietitians and physiotherapists to provide positive feedback and discuss behaviour maintenance (goal setting and self-monitoring) and relapse prevention; (iv) a return visit with dietitians and physiotherapists three months after the end of the intervention to motivate and support participants in maintaining a healthy lifestyle. The fifth and final element of the maintenance programme was monitoring by practice nurses after the end of the intervention. This involved discussing and monitoring participants' behaviour change during regular consultations at the general practice in the following months and years. This element was therefore beyond the scope of the process evaluation.

\section{Data collection and outcomes}

A process evaluation including quantitative and qualitative methods was conducted. Data from both HCP and intervention participants were collected between baseline (T0) and the end of the intervention (T1) and during the return visit three months after the end of the intervention.

\section{Process measures}

A process evaluation plan was designed based on the evaluation strategies of Steckler and Linnan ${ }^{(31)}$, Saunders et $a l^{(32)}$, Nutbeam ${ }^{(33)}$ and Wang et $a l^{(34)}$. Process evaluation data were collected and used to investigate how the SLIMMER intervention was delivered and received in Dutch primary health care and to explain intervention effectiveness. The following process measures were included and are described below: recruitment, reach, dose received, acceptability, implementation integrity, applicability and context.

Recruitment was defined as procedures used to approach and attract participants ${ }^{(31)}$. Recruitment procedures and barriers were evaluated using semi-structured telephone interviews with practice nurses, three months after the intervention started ( $n$ 19, average duration $27 \mathrm{~min}$ ). All practice nurses involved in the implementation of the SLIMMER intervention were invited to these interviews by one of the researchers (G.D.). A semi-structured interview guide was developed and all interviews were conducted by one of the researchers (G.D.).

Reach was defined as the proportion of the intended target audience that participated in the intervention ${ }^{(31)}$. To assess the number of subjects willing to participate, the project logbook was consulted. Data on sociodemographic characteristics of both participants and nonresponders were collected with a survey according to Dutch national standards ${ }^{(35)}$. Dropouts were defined as participants who had both no T1 measurement for fasting insulin and/or BMI, and dropped out of the dietary and PA programme before the end of the intervention.

Dose received was defined as the extent to which participants actively engaged in intervention activities ${ }^{(31)}$. 
Table 1 Details of the SLIMMER lifestyle intervention programme according to the implementation manual

\begin{tabular}{|c|c|c|c|c|}
\hline Intervention components & Sub-components & Number & Time (min) & Details \\
\hline \multirow[t]{2}{*}{ Dietary intervention } & Consultations (incl. intake) & $\begin{array}{c}5-8 \\
\text { (individual) }\end{array}$ & Max. 240 & $\begin{array}{l}\text { - Aim: adopt sustainable healthy dietary pattern; } 5-10 \% \text { weight loss } \\
\text { - } 60 \text { min intake consultation to obtain information on social and environmental factors, } \\
\text { perform dietary assessment and set goals } \\
\text { Formulate treatment plan (including goals and advice) } \\
\text { - Inform, advise and guide participants in adapting dietary pattern } \\
\text { - Based on Dutch dietary guidelines }{ }^{(28)} \\
\text { - Discuss topics: Dutch dietary guidelines, fats, carbohydrates and fibre, sweeteners, } \\
\text { special occasions, and explain the relationship between nutrition and glucose tolerance } \\
\text { Make use of motivational interviewing and positive feedback } \\
\text { - Spouses could join } \\
\text { Set, evaluate and adjust goals } \\
\text { - Divide consultations over } 10 \text { months }\end{array}$ \\
\hline & Group meeting & $\begin{array}{c}1 \\
\text { (group-based) }\end{array}$ & 90 & $\begin{array}{l}\text { - Aim: share experiences, motivate one another and provide information } \\
\text { Discuss topic: label reading } \\
\text { - Compare products on fat and sugar content } \\
\text { Plan this group meeting halfway through the intervention }\end{array}$ \\
\hline \multirow[t]{3}{*}{$\begin{array}{l}\text { Physical activity (PA) } \\
\text { intervention }\end{array}$} & Intake & $\begin{array}{c}1 \\
\text { (individual) }\end{array}$ & 30 & $\begin{array}{l}\text { - Aim: obtain information on current PA, needs, abilities, motivation and barriers to PA } \\
\text { Set goals }\end{array}$ \\
\hline & Sports lessons & $\begin{array}{l}40-80 \\
\text { (group-based) }\end{array}$ & $\begin{array}{l}60 \\
\text { (per lesson) }\end{array}$ & $\begin{array}{l}\text { - Aim: achieve moderate-intensity PA for at least } 30 \mathrm{~min} / \mathrm{d} \text { at least five days per week } \\
2 / 3 \mathrm{rd} \text { of training is aerobic exercise }\left(60-70 \% \text { of } \mathrm{VO}_{2} \mathrm{max}\right) \\
\text { - } 1 / 3 \text { rd of training is resistance exercise (55-60\% of } 1 \text { repetition maximum, with } 3 \times 15 \\
\text { repetitions, for major muscle groups) } \\
\text { - Offer group-based activities } \\
\text { - Individually tailored guidance } \\
\text { - Improve level of ability }\end{array}$ \\
\hline & Advice on PA during leisure time & - & - & $\begin{array}{l}\text { - Aim: encourage participants to be physically active during leisure time } \\
\text { - Discuss PA possibilities during leisure time } \\
\text { - If necessary: formulate an individual plan for PA during leisure time }\end{array}$ \\
\hline Case management & $\begin{array}{l}\text { Contact with health-care } \\
\text { professionals and participants }\end{array}$ & $\begin{array}{l}2 \text { phone calls } \\
\text { (individual) }\end{array}$ & - & $\begin{array}{l}\text { - Aim: monitor participants' progress } \\
\text { - Facilitate contact among health-care professionals } \\
\text { - Detect and solve problems } \\
\text { - Motivate and encourage participants }\end{array}$ \\
\hline \multirow[t]{4}{*}{ Maintenance programme } & $\begin{array}{l}\text { Intermediate evaluations by dietitians and } \\
\text { physiotherapists }\end{array}$ & $\begin{array}{l}3 \\
\text { (individual) }\end{array}$ & - & $\begin{array}{l}\text { - Aim: keep participants motivated, prevent dropout (at } 3,6 \text { and } 9 \text { months) } \\
\text { - Arovide feedback and discuss experiences with programme } \\
\text { and body fat percentage) } \\
\text { - Evaluate personal goals and adjust goals if necessary } \\
\text { - Stimulate self-management }\end{array}$ \\
\hline & Sports clinics & $\begin{array}{l}2-7 \\
\text { (group-based) }\end{array}$ & $\begin{array}{l}60 \\
\text { (per clinic) }\end{array}$ & $\begin{array}{l}\text { - Aim: introduce participants to different types of sports and sports organisations } \\
\text { to achieve sustainable behaviour change } \\
\text { - During times of reqular sport lessons }\end{array}$ \\
\hline & $\begin{array}{l}\text { Final interview dietitian/ } \\
\text { physiotherapist }\end{array}$ & $\stackrel{2}{2}$ (individual) & - & $\begin{array}{l}\text { - Aim: strengthen participants' self-efficacy and motivation } \\
\text { - One final interview with dietitian during last consultation and one final interview with } \\
\text { physiotherapist during last sports lesson } \\
\text { - Provide positive feedback } \\
\text { - Discuss behaviour maintenance (goal setting and self-monitoring) } \\
\text { - Inform about relapse prevention }\end{array}$ \\
\hline & Return visit & $\begin{array}{c}1 \\
\text { (group-based) }\end{array}$ & 60 & $\begin{array}{l}\text { - Aim: prevent relapse and motivate and support participants to maintain behaviour change } \\
\text { Dietitian and physiotherapist are present } \\
\text { - Discuss behaviour maintenance during last } 3 \text { months/share experiences } \\
\text { - Measurements of weight, waist circumference and body fat percentage } \\
\text { - Provide tips for behaviour maintenance }\end{array}$ \\
\hline
\end{tabular}


The following items were assessed from registration forms: the number and total minutes of dietary consultations; the number of one-hour sports lessons, case management phone calls and sports clinics; the number of participants attending final interviews; the number of participants attending the dietary group meeting; and the number of participants attending the return visit.

Acceptability was defined as the extent to which participants and HCP were satisfied with the intervention ${ }^{(32)}$. Participants' acceptability of the intervention was assessed using evaluation forms after the dietary group meeting, sports clinics and return visit, and questionnaires at the end of the intervention. Acceptability of the intervention by HCP was assessed using semi-structured telephone interviews. All HCP were invited by one of the researchers (G.D.) three months after starting the intervention (practice nurses, $n$ 19, average duration $27 \mathrm{~min}$; dietitians, $n$ 11, average duration $34 \mathrm{~min}$; physiotherapists, $n$ 15, average duration $31 \mathrm{~min}$ ) and at the end of the intervention (practice nurses, $n$ 11, average duration $23 \mathrm{~min}$; dietitians, $n 9$, average duration $28 \mathrm{~min}$; physiotherapists, $n 12$, average duration $25 \mathrm{~min}$ ). A semi-structured interview guide was developed and all interviews were conducted by one of the researchers (G.D.). Acceptability of the intervention by participants and by HCP was rated on a 7-point or a 10-point scale. To make results comparable, all acceptability ratings were expressed as a percentage of maximum.

Implementation integrity was defined as the extent to which the intervention was implemented as planned ${ }^{(31,33)}$. Applicability was defined as the extent to which the intervention process could be implemented in a real-world setting ${ }^{(34)}$. These measures were assessed by semistructured interviews and questionnaires with HCP as described above.

Context was defined as aspects of the larger physical, social and political environment that either directly or indirectly affect intervention implementation ${ }^{(31)}$. Participant questionnaires and semi-structured interviews with $\mathrm{HCP}$, as described above, were used to investigate aspects that affect intervention implementation. Our analysis regarding context aspects provided no additional information to that elicited in relation to acceptability, integrity and applicability.

\section{Explain intervention effectiveness}

To explain intervention effectiveness, associations between process measures (dose received and acceptability) and health outcomes and lifestyle behaviours (fasting insulin, weight, dietary intake and PA) were investigated. Dose received was defined as attending dietary consultations (in number of consultations) and as attending sports lessons (in number of lessons). Participants' acceptability of the total SLIMMER intervention (score 1-10) was ascertained in a questionnaire at the end of the intervention (T1).
To assess health outcomes, clinical assessments were performed by trained research assistants in research centres in Apeldoorn and Doetinchem. This has been described in detail elsewhere ${ }^{(24,25)}$. In short, participants were measured at baseline (T0) and after the intervention (T1). A standard oral glucose tolerance test (glucose load $75 \mathrm{~g}$ ) was performed by a trained nurse after at least $10 \mathrm{~h}$ of fasting. Fasting serum insulin, our primary outcome ${ }^{(25)}$, was determined at SHO Laboratory in Velp, the Netherlands. Dietary intake was assessed by a validated $\mathrm{FFQ}^{(36,37)}$. The FFQ were checked by trained research assistants. Adherence to the Dutch dietary guidelines was calculated with an adapted Dutch Healthy Diet Index (DHD-index $)^{(24,38,39)}$, which included eight components; namely, PA, vegetables, fruit, fibre, fish (EPA and DHA), saturated fat, trans-fatty acids and alcohol. Per component, the score ranged between 0 and 10 , resulting in a total score between 0 (no adherence) and 80 (complete adherence). PA was measured using the validated Short Questionnaire to Assess Health-enhancing physical activity (SQUASH), including questions on commuting activities, leisure-time activities, household activities and activities at work ${ }^{(40,41)}$. The duration (minutes per week) of vigorous-intensity physical activities was calculated.

\section{Data analysis}

Quantitative data were analysed using the statistical software package IBM SPSS Statistics Version 22 with complete cases for the item of interest (ranging from seventy-eight to 155 intervention participants per analysis). Differences between intervention and control participants and non-responders (those who were invited but not willing to participate) were tested for statistical significance with independent-samples $t$ tests, one-way ANOVA and $\chi^{2}$ tests. Descriptive statistics were used to analyse dose received and acceptability and applicability scores. Associations between process measures and health outcomes and lifestyle behaviours were assessed with linear regression analysis, adjusted for baseline value, sex and recruitment phase.

Qualitative data analyses were performed using an inductive approach ${ }^{(42)}$. Interviews with HCP were audiotaped and transcribed verbatim. All transcripts were read by two researchers (E.J.I.v.D. and G.D.) individually to identify frequently emerging themes within predefined topics and these were discussed until agreement was reached. These themes were used to create a coding scheme in the qualitative data analysis software package Atlas.ti version 7 .

\section{Results}

\section{Recruitment and reach}

In total, twenty-five general practices (general practitioners and practice nurses), eleven dietitians, nine 
Table 2 Baseline characteristics of participants $(n$ 316) and non-responders ( $n$ 175) in the SLIMMER intervention*

\begin{tabular}{|c|c|c|c|c|c|c|}
\hline & \multicolumn{2}{|c|}{ Intervention group ( $n$ 155) } & \multicolumn{2}{|c|}{ Control group ( $n$ 161) } & \multicolumn{2}{|c|}{ Non-responders ( $n$ 175) } \\
\hline & Mean or \% & SD & Mean or $\%$ & SD & Mean & SD \\
\hline$n$ (male/female) $\dagger$ & $81 / 74$ & & $80 / 81$ & & $87 / 87$ & \\
\hline Age (years) & $60 \cdot 7$ & $6 \cdot 4$ & 61.0 & $6 \cdot 5$ & 60.9 & $7 \cdot 0$ \\
\hline \multicolumn{7}{|l|}{ Education (\%)‡,§ } \\
\hline Low & $54 \cdot 0$ & & $51 \cdot 0$ & & $52 \cdot 0$ & \\
\hline Middle & $26 \cdot 0$ & & $21 \cdot 0$ & & $27 \cdot 0$ & \\
\hline High & $20 \cdot 0$ & & 28.0 & & 21.0 & \\
\hline \multicolumn{7}{|l|}{ Perceived health (\%)\| } \\
\hline Poor/fair & $21 \cdot 0$ & & $21 \cdot 0$ & & $10 \cdot 0$ & \\
\hline Good & 68.0 & & $70 \cdot 0$ & & $74 \cdot 0$ & \\
\hline Very good/excellent & $11 \cdot 0$ & & $9 \cdot 0$ & & $16 \cdot 0$ & \\
\hline \multicolumn{7}{|l|}{ Ethnicity (\%) } \\
\hline Dutch & 88.0 & & $89 \cdot 0$ & & & \\
\hline Western non-Dutch & $9 \cdot 0$ & & 8.0 & & & \\
\hline Non-Western non-Dutch & 3.0 & & 3.0 & & & \\
\hline \multicolumn{7}{|l|}{ Employment status (\%) } \\
\hline No paid job & $54 \cdot 0$ & & $52 \cdot 0$ & & & \\
\hline Part-time job (<32 h/week) & $18 \cdot 0$ & & $22 \cdot 0$ & & & \\
\hline Full-time job ( $\geq 32 \mathrm{~h} /$ week) & 28.0 & & $26 \cdot 0$ & & & \\
\hline \multicolumn{7}{|l|}{ Family history of diabetes (\%) } \\
\hline No & $32 \cdot 0$ & & $42 \cdot 0$ & & & \\
\hline First degree & $49 \cdot 0$ & & $45 \cdot 0$ & & & \\
\hline Second degree & $19 \cdot 0$ & & 13.0 & & & \\
\hline BMI $\left(\mathrm{kg} / \mathrm{m}^{2}\right) \emptyset$ & $30 \cdot 4$ & 4.7 & $30 \cdot 0$ & $4 \cdot 8$ & & \\
\hline Fasting insulin (pmol/l) & $93 \cdot 3$ & $64 \cdot 3$ & 82.5 & $50 \cdot 2$ & & \\
\hline \multicolumn{7}{|c|}{$\begin{array}{l}\text { *Data are mean and SD or \%. } \\
\dagger n 174 \text { for non-responders. } \\
\ddagger n 155 \text { for intervention group, } n 160 \text { for control group and } n 96 \text { for non-responders. } \\
\S \text { Education level was based on the highest level of education completed and divided in three categories: low (primary school or less } \\
\text { lower vocational education), middle (medium vocational education, high school) and high (higher vocational education, university). } \\
\text { In } n 115 \text { for non-responders. } \\
\text { I } n 154 \text { for intervention group and } n 161 \text { for control group. }\end{array}$} \\
\hline
\end{tabular}

physiotherapist practices (including sixteen physiotherapists) and fifteen sports clubs were involved in the implementation of the SLIMMER intervention. Selection of patients from the general practitioners' registration database was perceived as difficult and time consuming by some practice nurses, but others perceived it as easy. Patients were often difficult to reach, but most practice nurses were persistent in trying to contact participants. Of the 590 subjects who were eligible and invited, 316 subjects (response rate 54\%) were willing to participate. For those not willing to participate, the most important reasons for non-response were lack of time (25\%), lack of interest (22\%), reporting 'I already exercise enough' (11\%), reporting 'It is of no importance to me' (10\%) and not able due to illness or handicap (9\%). No significant differences in baseline characteristics were observed between SLIMMER participants and non-responders or between the intervention and the control group (Table 2). On average, participants were 61 years old and most of them had a low education level, were Dutch and had a family history of diabetes. Of all participants, $48 \%$ were overweight (BMI $25 \cdot 0-29 \cdot 9 \mathrm{~kg} / \mathrm{m}^{2}$ ) and $43 \%$ were obese (BMI $\geq 30 \cdot 0 \mathrm{~kg} / \mathrm{m}^{2}$ ). In total, ten participants ( $7 \%$ ) dropped out of the intervention, mostly during the first ten weeks of the intervention period.

\section{Dose received}

Table 3 describes the dose of the SLIMMER intervention received by intervention participants. Overall, actual dose received was in line with the planned dose according to the manual. Most participants in the intervention group (84\%) received five or more individual consultations with the dietitian. On average, 5.6 consultations with a total duration of $3.4 \mathrm{~h}$ were attended. Participants attended on average thirty-eight sports lessons of one hour with the physiotherapist. The goal of participating at least once weekly (forty or more times in total) in the PA intervention was achieved by $41 \%$ of participants. Regarding the case management component of the intervention, $76 \%$ of participants indicated that they had contact at least once with the practice nurse, with $28 \%$ of participants having contact twice. More than two-thirds of the participants (71\%) attended at least one sports clinic at a local sports club, with an average number of 2.3 clinics attended per participant. Sixty-one per cent of participants attended the final interviews and received materials on maintenance, and $58 \%$ attended the return visit with the dietitian and physiotherapist, three months after the end of the intervention.

\section{Acceptability}

Overall, participants and HCP were highly satisfied with the SLIMMER intervention, with mean acceptability rating 
Table 3 Dose of the SLIMMER intervention components received by the intervention group $(n 155)^{*}$

\begin{tabular}{|c|c|c|c|}
\hline \multirow[b]{2}{*}{ Intervention component } & \multirow[b]{2}{*}{ Intervention manual } & \multicolumn{2}{|c|}{ Dose received } \\
\hline & & Mean or $\%$ & SD \\
\hline \multicolumn{4}{|l|}{ Dietary intervention } \\
\hline \multicolumn{4}{|l|}{ Individual consultations } \\
\hline Number & 5-8 (incl. intake) & $5 \cdot 6$ & 1.4 \\
\hline Total time (hours) & Max. $4 \mathrm{~h}$ & 3.4 & 0.8 \\
\hline Group meeting (\%) & Attend 1 group meeting & $67 \cdot 0$ & \\
\hline \multicolumn{4}{|l|}{ Physical activity intervention } \\
\hline Number of sports lessons & At least once per week $=40$ times & 38.0 & $20 \cdot 8$ \\
\hline \multicolumn{4}{|l|}{ Case management } \\
\hline Phone calls by practice nurse $(\%) \dagger$ & Twice & & \\
\hline Never & & $24 \cdot 0$ & \\
\hline Once & & $48 \cdot 0$ & \\
\hline Twice & & 28.0 & \\
\hline \multicolumn{4}{|l|}{ Maintenance programme } \\
\hline Number of clinics & $2-7$ & $2 \cdot 3$ & 1.9 \\
\hline Final interview (\%)‡ & Materials provided during last consultation with dietitian & 61.0 & \\
\hline Return visit (\%) & Attend 1 return visit & 58.0 & \\
\hline
\end{tabular}

*Data are mean and SD or \%.

†n 143.

$\ddagger$ Based on the number of participants receiving materials on maintenance distributed during final interview.

Table 4 Acceptability (score $0-100)$ of the SLIMMER intervention by the intervention group $(n 144)$ and health-care professionals $(n 44)^{\star}$

\begin{tabular}{|c|c|c|c|c|}
\hline & \multicolumn{2}{|c|}{ Participants } & \multicolumn{2}{|c|}{ Professionals } \\
\hline & Mean or \% & SD & Mean or $\%$ & SD \\
\hline \multicolumn{5}{|l|}{ Overall } \\
\hline Total SLIMMER intervention & $82.0 \dagger$ & $11 \cdot 0$ & $80 \cdot 0$ & $5 \cdot 0$ \\
\hline \multicolumn{5}{|l|}{ Dietary intervention } \\
\hline Individual consultations & $77 \cdot 0$ & $21 \cdot 0$ & $78 \cdot 0^{\star *}$ & $6 \cdot 0$ \\
\hline Group meeting & $80.0 \neq$ & 8.0 & & \\
\hline \multicolumn{5}{|l|}{ Physical activity intervention } \\
\hline Sports lessons & $84.0 \S$ & $20 \cdot 0$ & 78.0†† & $7 \cdot 0$ \\
\hline \multicolumn{5}{|l|}{ Case management } \\
\hline Contact with practice nurse & $66.0 \S$ & $21 \cdot 0$ & & \\
\hline \multicolumn{5}{|l|}{ Maintenance programme } \\
\hline Indicates final interview with dietitian as helpful (\%) & $76 \cdot 0 \|$ & & & \\
\hline Indicates final interview with physiotherapist as helpful (\%) & 68.011 & & & \\
\hline Sports clinics & $77.0 \pi$ & $20 \cdot 0$ & & \\
\hline Return visit & $80.0 \pi$ & 13.0 & & \\
\hline
\end{tabular}

${ }^{*}$ Data are mean and SD or percentage.

$\dagger n 142$.

$\ddagger n 99$.

$\S n 143$.

\|n 78 for percentage of participants who perceived the advice during the final interview as helpful.

In 118.

${ }^{\star *} n 9$ dietitians.

$\dagger \dagger n 8$ physiotherapists.

of 82 and 80, respectively (Table 4). Physiotherapists' scores decreased a little over time, mostly because they experienced the organisation of sports clinics during the last phase of the intervention period as not always optimal (e.g. clinics at times deviating from regular sports lesson times). HCP were convinced of the added value of the SLIMMER intervention, were positive about the communication with the project team and the multidisciplinary nature of the programme, and perceived the intensive guidance of participants as a strength. According to HCP, inclusion criteria might be sharpened, as several participants already had a healthy lifestyle at the start of the intervention and therefore could not improve much more, resulting in low motivation in these participants. HCP felt involved in the SLIMMER intervention, although practice nurses indicated that the focus of their involvement was mostly at the beginning of the project. Data on acceptance of the specific intervention components are presented below.

\section{Dietary intervention}

In general, participants and dietitians were satisfied with the individual consultations with the dietitian, with mean score of 77 and 78, respectively (Table 4). Participants 
were also positive about the number of consultations, the guidance of the dietitian and the tailoring of advice.

\section{Physical activity intervention}

Both participants and physiotherapists were positive about the weekly sports lessons, scoring a mean appreciation of 84 and 78, respectively (Table 4). Participants were satisfied with physiotherapists' guidance and appreciated the programme being tailored to their personal needs. Furthermore, participants preferred group-based sports lessons. Four HCP indicated that the fact that sports lessons were group-based was important for support and motivation.

\section{Case management}

Participants were reasonably satisfied with the contact with practice nurses (score of 66; Table 4). Several practice nurses indicated that, besides monitoring progress, showing their engagement with participants was an important aspect of phone calls with participants.

\section{Maintenance programme}

Overall, participants perceived final interviews with the dietitian and physiotherapist as helpful $(76 \%$ and $68 \%$, respectively; Table 4 ), and they were satisfied with the sports clinics and return visit (score of 77 and 80, respectively; Table 4). They appreciated guidance of HCP during the return visit and the fact that this meeting was group-based. Physiotherapists thought sports clinics were a good way to introduce participants to several sports and to reduce barriers to joining a sports club.

\section{Implementation integrity}

\section{Dietary intervention}

The number of consultations, time schedule and topics to discuss were individually tailored to participants' wishes and needs, and goals were set and evaluated during consultations. Some dietitians deviated from the Dutch dietary guidelines by advising a low-carbohydrate diet. Motivational interviewing was used by all dietitians, albeit to a varying extent, and all dietitians gave positive feedback to participants. Sometimes not all components of the group meeting were implemented because of lack of time.

\section{Physical activity intervention}

Both aerobic and resistance exercises were incorporated and implemented according to the manual. Intensity of training and type of exercise were individually tailored on the basis of test results or physiotherapists' judgement. Goals were set at the start of the PA intervention and physiotherapists provided feedback during sports lessons. Tailored advice on PA in daily life was given. However, physiotherapists indicated that not all participants needed this stimulation. Furthermore, physiotherapists stated that they were able to give individual guidance during sports lessons, unless groups were too large. Group cohesion was facilitated by most physiotherapists during joint exercises at the end of the sports lessons.

\section{Case management}

Referral of participants to dietitians and physiotherapists was perceived as easy and normal by most practice nurses. Most practice nurses have had contact with HCP and participants as part of their case management role. Sometimes, emails were used instead of phone calls to save time, and in some cases case management was omitted because of lack of time. Although case management was aimed at solving problems and motivating participants, practice nurses almost never had to do this. No contact and collaboration between HCP other than the phone calls was reported.

\section{Maintenance programme}

Dietitians and physiotherapists provided feedback on participants' progress during intermediate evaluations, according to the manual. Physiotherapists indicated that the intensity of sports clinics did not always match participants' level of ability and that some sports clinics were less intensive than regular SLIMMER sports lessons. Furthermore, they suggested that it would be better to introduce sports clinics earlier in the programme to slowly familiarise participants with a variety of sports. All dietitians and physiotherapists conducted final interviews with participants and discussed maintenance of behaviour change by giving advice on self-monitoring (e.g. weigh yourself regularly) and goal setting (e.g. make an action plan). Furthermore, they informed participants about relapse prevention (e.g. contact HCP if needed). Overall, the return visit was implemented as planned according to the manual, and dietitians and physiotherapists perceived an equal distribution of tasks. However, not all suggested measurements were performed by all HCP.

\section{Applicability}

Most HCP indicated that in general the SLIMMER intervention was not very different from their regular functioning and professional performance. Some practice nurses, however, indicated deviations from their daily practice, mainly regarding a different role perception in that they referred participants to dietitians and physiotherapists for lifestyle advice instead of providing this advice themselves. Some dietitians indicated that normally they were more flexible in planning consultations. Furthermore, dietitians perceived dietary consultations as difficult if participants themselves did not feel the need for these (compulsory) consultations or lacked motivation. All HCP indicated that it was possible to implement SLIMMER in daily practice, although they foresaw financial barriers. Furthermore, they indicated that contact between dietitians and physiotherapists was limited because their respective networks do not overlap and therefore better collaborations need to be built in order to be able to work in a multidisciplinary way. 


\section{Explain intervention effectiveness}

A higher dose of sports lessons, that is, higher attendance at the PA programme, was associated with increased weight loss $(P=0.001$; Table 5$)$. A higher dose of dietary consultations was not associated with a higher DHD-index score. Participants' acceptability of the intervention was associated with beneficial changes in fasting insulin $(P=0.044)$ and weight $(P<0.001)$. Neither dose received nor acceptability was associated with changes in vigorous activities.

\section{Discussion}

The current process evaluation gave insight into how the SLIMMER intervention was delivered and received in Dutch primary health care and how this could explain intervention effectiveness. We were able to recruit the intended high-risk target population and the SLIMMER intervention was very well received by both participants and HCP. The intervention programme was to a large extent implemented as planned and was applicable in Dutch primary health care. Dose received and acceptability were related to health outcomes and dietary behaviour, but not to PA behaviour.

We designed and used an extensive process evaluation plan to evaluate implementation and provide insight into the effectiveness of the SLIMMER intervention. Nowadays, the value of process evaluation within trials is recognised and recently the Medical Research Council developed guidance on process evaluation of public health interventions ${ }^{(17)}$. Several studies have investigated intervention implementation $^{(43-48)}$; however, results are difficult to compare because a systematic approach to process evaluation has not been used and consequently a wide range of process indicators and methods are reported in publications.

Recruitment of participants was perceived as difficult and time consuming by some practice nurses. Issues related mainly to improper registration of blood glucose values in the patient registration database and to technical problems retrieving information from this database. However, the response rate (54\%) was comparable with the SLIMMER pilot study $(57 \%)^{(23)}$.

Participants' acceptability was high with mean acceptability scores of about 80 on a scale of $0-100$. Participants appeared to be least satisfied with the practice nurse. This could be explained by the minor role of the practice nurse in the intervention programme, making it more difficult for participants to remember or recognise this.

The high implementation integrity might be due to the careful and long initial period of translating ${ }^{(22)}$ and pilottesting the SLIMMER intervention ${ }^{(23)}$ and the fact that we built on existing structures in primary health care. We believe that implementation becomes more successful if capacity is built and networks are formed among local partner organisations.

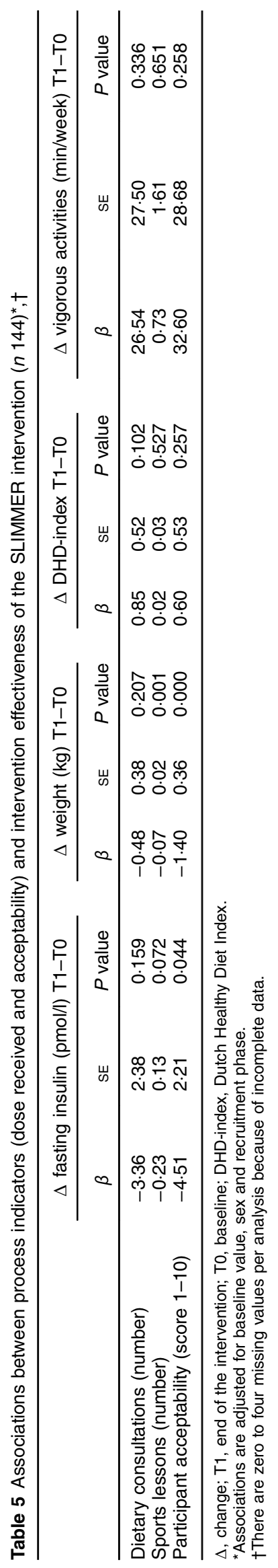


To ensure intervention effectiveness, it is essential to include the intervention components most strongly associated with effectiveness ${ }^{(18)}$. Our regression analysis showed that higher intervention intensity (dose received) was associated with weight loss, but not with change in dietary and PA behaviour. This is in line with the results of several systematic reviews ${ }^{(18-20,49)}$, although other reviews found no associations with intervention intensity ${ }^{(21,50)}$. As no clear evidence exists for a particular minimum threshold for intervention intensity ${ }^{(18)}$, more research is needed to determine the optimum. Explanations for not finding an association between intervention intensity and dietary behaviour might include the fact that adherence to the Dutch dietary guidelines was already high at baseline or that there was not much variation in the number of consultations between participants. Not finding an association between intervention intensity and PA behaviour might be explained by the fact that vigorous activities, as an outcome indicator, does not cover all physical activities. Furthermore, participants who perform vigorous activities during the sports lessons might compensate for this in their leisure time. In addition, our analysis showed that higher participant satisfaction was associated with increased weight loss. Appreciation of the programme might be important for intervention compliance. This in turn leads to a higher intervention intensity, which we have shown was associated with better outcomes.

The intervention effectiveness might also have been facilitated by other components incorporated in the SLIMMER intervention, as suggested Greaves et al.'s ${ }^{(18)}$ review: targeting both diet and PA, using behaviour change techniques (goal setting, self-monitoring, relapse prevention) and focusing on behaviour maintenance. Furthermore, the high level of individual tailoring of the dietary and PA programme, which was appreciated by participants, might have contributed to effectiveness ${ }^{(20)}$. Also, deploying specialists - dietitians and physiotherapists rather than generalists for lifestyle counselling may have contributed to intervention effectiveness. A systematic review by van Dillen and Hiddink ${ }^{(51)}$ found general practitioners and practice nurses, who are considered generalists, able to provide lifestyle counselling in primary health care. However, they provided rather general lifestyle advice and experienced lack of time and competency issues. Therefore, cooperation with specialists was needed and recommended $^{(51)}$. Another systematic review suggested that a wide range of staff could deliver effective interventions ${ }^{(18)}$. Therefore, a multidisciplinary approach with both specialists and generalists, such as in our study, might be the best way to utilise expertise fully, thereby contributing to intervention effectiveness.

A limitation of the study might be the risk of recall bias by HCP providing data on implementation of the intervention. Furthermore, interviews were conducted by the researcher who was also the contact person for HCP during the study. However, HCP were not hesitant to criticise the intervention and to mention points for improvement. Our study has several strengths. First, we used an extensive process evaluation plan, including several process indicators measured both quantitatively and qualitatively. This provided a profound understanding of the delivery of the intervention and gave insight into possible aspects that might explain intervention effectiveness. Second, triangulation is considered a strength of our study. By the combination of multiple methods (registration forms, questionnaires, semi-structured interviews), incorporating both participants and HCP, and by two researchers analysing the data independently, the credibility and the validity of our results have been increased. Third, our study had a high response rate from participants and professionals who provided input for the process evaluation: $50-100 \%$ of participants provided data dependent on the item of interest and almost all involved HCP (90\%) participated in interviews.

\section{Conclusions}

In summary, the present study has shown that it is feasible to implement a diabetes prevention intervention in Dutch primary health care. Higher dose received and participant acceptability were associated with improved health outcomes and dietary behaviour, but not with PA behaviour. Furthermore, targeting both diet and PA, using behaviour change techniques, focusing on behaviour maintenance, tailoring the intervention and using a multidisciplinary approach might have facilitated effectiveness. Using an extensive process evaluation plan to gain insight into how an intervention is delivered and received is a valuable way of identifying intervention components that contribute to implementation integrity and effective prevention of type 2 diabetes in primary health care.

\section{Acknowledgements}

Acknowledgements: The authors thank all participants and health-care professionals who were involved in the SLIMMER study. The authors gratefully acknowledge Ellen Elsman and Marleen van Hattem for their help in transcribing interviews. The authors also thank the local steering committees of Apeldoorn and Doetinchem (community health service, municipality, health insurer, regional supporting organisation for primary care (ROS), general practitioners, physiotherapists and dietitians) for facilitating implementation of the intervention. Financial support: This work was supported by the Netherlands Organization for Health Research and Development ZonMw (grant numbers 87600048 and 20400.7003); and the Dutch Diabetes Research Foundation (grant number 2011.15.1462). The Netherlands Organization for Health Research and Development ZonMw and the Dutch Diabetes Research Foundation had no role in the design, 
analysis or writing of this article. Conflict of interest: None. Authorship: E.J.I.v.D. and G.D. contributed equally to the contents of the manuscript. G.D. designed the process evaluation study. G.D. and E.J.I.vD collected and analysed the data and drafted the manuscript. S.C.J. and J.t.B. participated in the study design and implementation in public health and primary care, and helped to draft the manuscript. J.M.H., J.N.L., A.H.-N., G.J.H. and E.J.M.F. made major revisions to the manuscript. All authors contributed to the development of the SLIMMER intervention, and read and approved the final manuscript. Ethics of buman subject participation: This study was conducted according to the guidelines laid down in the Declaration of Helsinki and all procedures involving human subjects were approved by the Wageningen University Medical Ethics Committee. Written informed consent was obtained from all subjects.

\section{References}

1. Yoon U, Kwok LL \& Magkidis A (2013) Efficacy of lifestyle interventions in reducing diabetes incidence in patients with impaired glucose tolerance: a systematic review of randomized controlled trials. Metab Clin Exp 62, 303-314.

2. Tuomilehto J, Lindström J, Eriksson JG et al. (2001) Prevention of type 2 diabetes mellitus by changes in lifestyle among subjects with impaired glucose tolerance. $N$ Engl J Med 344, 1343-1350.

3. Knowler W, Barrett-Connor E, Fowler S et al. (2002) Reduction in the incidence of type 2 diabetes with lifestyle intervention or metformin. N Engl J Med 346, 393-403.

4. Roumen C, Corpeleijn E, Feskens EJM et al. (2008) Impact of 3 -year lifestyle intervention on postprandial glucose metabolism: the SLIM study. Diabet Med 25, 597-605.

5. Lindström J, Peltonen M, Eriksson JG et al. (2013) Improved lifestyle and decreased diabetes risk over 13 years: longterm follow-up of the randomised Finnish Diabetes Prevention Study (DPS). Diabetologia 56, 284-293.

6. Diabetes Prevention Program Research Group (2009) 10-year follow-up of diabetes incidence and weight loss in the Diabetes Prevention Program Outcomes Study. Lancet 374, 1677-1686.

7. Li G, Zhang P, Wang J et al. (2014) Cardiovascular mortality, all-cause mortality, and diabetes incidence after lifestyle intervention for people with impaired glucose tolerance in the Da Qing Diabetes Prevention Study: a 23-year followup study. Lancet Diabetes Endocrinol 2, 474-480.

8. Roumen C, Feskens EJM, Corpeleijn E et al. (2011) Predictors of lifestyle intervention outcome and dropout: the SLIM study. Eur J Clin Nutr 65, 1141-1147.

9. Johnson M, Jones R, Freeman C et al. (2013) Can diabetes prevention programmes be translated effectively into realworld settings and still deliver improved outcomes? A synthesis of evidence. Diabet Med 30, 3-15.

10. Cardona-Morrell M, Rychetnik L, Morrell S et al. (2010) Reduction of diabetes risk in routine clinical practice: are physical activity and nutrition interventions feasible and are the outcomes from reference trials replicable? A systematic review and meta-analysis. BMC Public Health 10, 653 .

11. Kahn R \& Davidson MB (2014) The reality of type 2 diabetes prevention. Diabetes Care 37, 943-949.

12. Dunkley AJ, Bodicoat DH, Greaves CJ et al. (2014) Diabetes prevention in the real world: effectiveness of pragmatic lifestyle interventions for the prevention of type 2 diabetes and of the impact of adherence to guideline recommendations - a systematic review and meta-analysis. Diabetes Care 37, 922-933.

13. Garfield SA, Malozowski S, Chin MH et al. (2003) Considerations for diabetes translational research in real-world settings. Diabetes Care 26, 2670-2674.

14. Glasgow RE, Vogt TM \& Boles SM (1999) Evaluating the public health impact of health promotion interventions: the RE-AIM framework. Am J Public Health 89, 1322-1327.

15. O'Hara BJ, Bauman AE, Eakin EG et al. (2013) Evaluation framework for translational research: Case Study of Australia's Get Healthy Information and Coaching Service ${ }^{\circledR}$. Health Promot Pract 14, 380-389.

16. Rychetnik L, Frommer M, Hawe P et al. (2002) Criteria for evaluating evidence on public health interventions. J Epidemiol Community Health 56, 119-127.

17. Moore GF, Audrey S, Barker M et al. (2015) Process evaluation of complex interventions: Medical Research Council guidance. BMJ 350, h1258.

18. Greaves CJ, Sheppard KE, Abraham C et al. (2011) Systematic review of reviews of intervention components associated with increased effectiveness in dietary and physical activity interventions. BMC Public Health 11, 119 .

19. Ashra NB, Spong R, Carter P et al. (2015) A Systematic Review and Meta-Analysis Assessing the Effectiveness of Pragmatic Lifestyle Interventions for the Prevention of Type 2 Diabetes Mellitus in Routine Practice. London: Public Health England.

20. Hobbs N, Godfrey A, Lara J et al. (2013) Are behavioral interventions effective in increasing physical activity at 12 to 36 months in adults aged 55 to 70 years? A systematic review and meta-analysis. BMC Med 11, 75.

21. Hartmann-Boyce J, Johns DJ, Jebb SA et al. (2014) Effect of behavioural techniques and delivery mode on effectiveness of weight management: systematic review, meta-analysis and meta-regression. Obes Rev 15, 598-609.

22. Jansen S, Haveman-Nies A, Duijzer G et al. (2013) Adapting the SLIM diabetes prevention intervention to a Dutch reallife setting: joint decision making by science and practice. BMC Public Health 13, 457.

23. Duijzer G, Haveman-Nies A, Jansen S et al. (2014) Feasibility and potential impact of the adapted SLIM diabetes prevention intervention in a Dutch real-life setting: the SLIMMER pilot study. Patient Educ Couns 97, 101-107.

24. Duijzer G (2016) Type 2 diabetes prevention from research to practice: the SLIMMER lifestyle intervention. PhD Thesis, Wageningen University.

25. Duijzer G, Haveman-Nies A, Jansen SC et al. (2014) SLIMMER: a randomised controlled trial of diabetes prevention in Dutch primary health care: design and methods for process, effect, and economic evaluation. BMC Public Health 14, 602 .

26. De Weerdt I, Kuipers B \& Kok G (2007) 'Kijk op diabetes' met perspectief voor de toekomst. Eindverslag van de eerste fase ('Look at diabetes' with Future Perspective. End Report of the First Phase). Amersfoort: Nederlandse Diabetes Federatie.

27. World Health Organization (2006) Definition and Diagnosis of Diabetes Mellitus and Intermediate Hyperglycemia: Report of a WHO/IDF Consultation. Geneva: WHO.

28. Health Council of the Netherlands (2006) Guidelines for a Healthy Diet 2006. Publication no. 2006/21E. The Hague: Health Council of the Netherlands.

29. Praet SFE, van Uden C, Hartgens F et al. (2009) KNGFStandaard Beweeginterventie Diabetes Mellitus Type 2 (Royal Dutch Society for Physical Therapy's Guidelines on Physical 
Activity Intervention Type 2 Diabetes Mellitus). Amersfoort: Koninklijk Nederlands Genootschap voor Fysiotherapie.

30. Elsman E, Leerlooijer J, ter Beek J et al. (2014) Using the intervention mapping protocol to develop a maintenance programme for the SLIMMER diabetes prevention intervention. BMC Public Health 14, 1108.

31. Steckler A \& Linnan L (2002) Process Evaluation for Public Health Interventions and Research. San Francisco, CA: Jossey-Bass.

32. Saunders RP, Evans MH \& Joshi P (2005) Developing a process-evaluation plan for assessing health promotion program implementation: a how-to guide. Health Promot Pract 6, 134-147.

33. Nutbeam D (1998) Evaluating health promotion - progress, problems and solutions. Health Promot Int 13, 27-44.

34. Wang S, Moss JR \& Hiller JE (2006) Applicability and transferability of interventions in evidence-based public health. Health Promot Int 21, 76-83.

35. RIVM (2005) Lokale en nationale monitor gezondheid Indicatoren voor de monitor volksgezondheid (Local and national monitor health - Indicators for the monitor public health). https://www.monitorgezondheid.nl/volksindicatoren. aspx (accessed November 2011).

36. Streppel MT, de Vries JH, Meijboom S et al. (2013) Relative validity of the food frequency questionnaire used to assess dietary intake in the Leiden Longevity Study. Nutr J 12, 75 .

37. Siebelink E, Geelen A \& de Vries JHM (2011) Self-reported energy intake by FFQ compared with actual energy intake to maintain body weight in 516 adults. Br J Nutr 106, 274-281.

38. Van Lee L, Geelen A, van Huysduynen E et al. (2012) The Dutch Healthy Diet index (DHD-index): an instrument to measure adherence to the Dutch guidelines for a healthy diet. Nutr J 11, 49.

39. Van Lee L, Feskens EJM, Hooft van Huysduynen EJC et al. (2014) The Dutch Healthy Diet index as assessed by $24 \mathrm{~h}$ recalls and FFQ: associations with biomarkers from a crosssectional study. J Nutr Sci $\mathbf{2}$, e40.

40. Wendel-Vos GCW, Schuit AJ, Saris WHM et al. (2003) Reproducibility and relative validity of the short questionnaire to assess health-enhancing physical activity. J Clin Epidemiol 56, 1163-1169.
41. De Hollander EL, Zwart L, de Vries SI et al. (2012) The SQUASH was a more valid tool than the OBiN for categorizing adults according to the Dutch physical activity and the combined guideline. J Clin Epidemiol 65, 73-81.

42. Thomas D (2006) A general inductive approach for analyzing qualitative data. Am J Eval 27, 237-246.

43. Berendsen BAJ, Kremers SPJ, Savelberg HHCM et al. (2015) The implementation and sustainability of a combined lifestyle intervention in primary care: mixed method process evaluation. BMC Fam Pract 16, 37.

44. Vermunt PW, Milder IE, Wielaard F et al. (2012) Implementation of a lifestyle intervention for type 2 diabetes prevention in Dutch primary care: opportunities for intervention delivery. BMC Fam Pract 13, 79.

45. Lakerveld J, Bot S, Chinapaw M et al. (2012) Process evaluation of a lifestyle intervention to prevent diabetes and cardiovascular diseases in primary care. Health Promot Pract 13, 696-706.

46. Rosecrans AM, Gittelsohn J, Ho LS et al. (2008) Process evaluation of a multi-institutional community-based program for diabetes prevention among First Nations. Health Educ Res 23, 272-286.

47. Wozniak L, Soprovich A, Mundt C et al. (2015) Contextualizing the proven effectiveness of a lifestyle intervention for type 2 diabetes in primary care: a qualitative assessment based on the RE-AIM framework. Can J Diabetes 39, Suppl. 3, S92-S99.

48. Absetz P, Valve R, Oldenburg B et al. (2007) Type 2 diabetes prevention in the 'real world': one-year results of the GOAL implementation trial. Diabetes Care 30, 2465-2470.

49. Ali M, Echouffo-Tcheugui J \& Williamson D (2012) How effective were lifestyle interventions in real-world settings that were modeled on the diabetes prevention program? Health Aff (Millwood) 31, 67-75.

50. Dansinger ML, Tatsioni A, Wong JB et al. (2007) Meta-analysis: the effect of dietary counseling for weight loss. Ann Intern Med 147, 41-50.

51. Van Dillen SME \& Hiddink GJ (2014) To what extent do primary care practice nurses act as case managers lifestyle counselling regarding weight management? A systematic review. BMC Fam Pract 15, 197. 